that the science is useful, usable and used ${ }^{9}$.

A high-level, transdisciplinary body of international experts in disaster-risk reduction should be established by national governments and international organizations dealing with disaster risks, with input from various sectors and civil society. Such a body would have the reach and influence - from local communities, businesses and governments - to raise people's awareness. The same findings presented by an independent scientist or article would not.

The main practical difficulties will be in incorporating the field's diverse information and practices into an assessment, and demonstrating to policy-makers that it need not take a extreme event to cause catastrophic human consequences $^{10}$. Government support for the process will be essential. Synergies must be found by combining and consolidating disaster-risk reduction efforts across UN institutions.

Disaster-risk management, climate change and sustainable development targets will need to be aligned. For example, there should be a coordinated assessment of the state of knowledge in disaster risk and its utility for supporting the UN Sustainable Development Goals and the UN Framework Convention on Climate Change.

Knowledge transfer will make communitybased resilience efforts possible. Illuminating findings, best practices and state-of-the-art modelling must become part of the evidencebased strategy for disaster-risk reduction.

Susan L. Cutter is professor of geography at the University of South Carolina in Columbia, USA. Alik Ismail-Zadeh is a senior scientist in applied geosciences at the Karlsruhe Institute of Technology, Karlsruhe, Germany, and at the Russian Academy of Sciences, Moscow, Russia. Irasema Alcántara-Ayala, Orhan Altan, Daniel N. Baker, Salvano Briceño, Harsh Gupta, Ailsa Holloway, David Johnston, Gordon A. McBean, Yujiro Ogawa, Douglas Paton, Emma Porio, Rainer K. Silbereisen, Kuniyoshi Takeuchi, Giovanni B. Valsecchi, Coleen Vogel, Guoxiong Wu. e-mail:scutter@sc.edu

1. Cutter, S. L. Chall. Sustain. 1, 72-79 (2014).

2. Ismail-Zadeh, A. \& Takeuchi, K. Nat. Hazard. 42, 459-467 (2007).

3. Palmer, L. Nature Clim. Change 3, 857-858 (2013).

4. Ismail-Zadeh, A. in Extreme Natural Hazards, Disaster Risks and Societal Implications (eds Ismail-Zadeh, A. et al.) 47-60 (Cambridge Univ. Press, 2014).

5. Gall, M., Nguyen, K. H. \& Cutter, S. L. Int. J. Disast. Risk Reduct. 12, 255-267 (2015).

6. McBean, G. A. Curr. Opin. Environ. Sustain. 4, 122-127 (2012).

7. Erisman, J. W., Brasseur, G., Ciais, P., van Eekeren, N. \& Theis, T. L. Nature 519, 151-153 (2015).

8. Burton, I. Environ. Hazard. 3, 139-141 (2001).

9. Boaz, A. \& Hayden, C. Evaluation 8, 440-453 (2002).

10.Cutter, S. L. J. Extrem. Events 1, 1-4 (2014).

Full author affiliations accompany this article online at go.nature.com/fihq6v

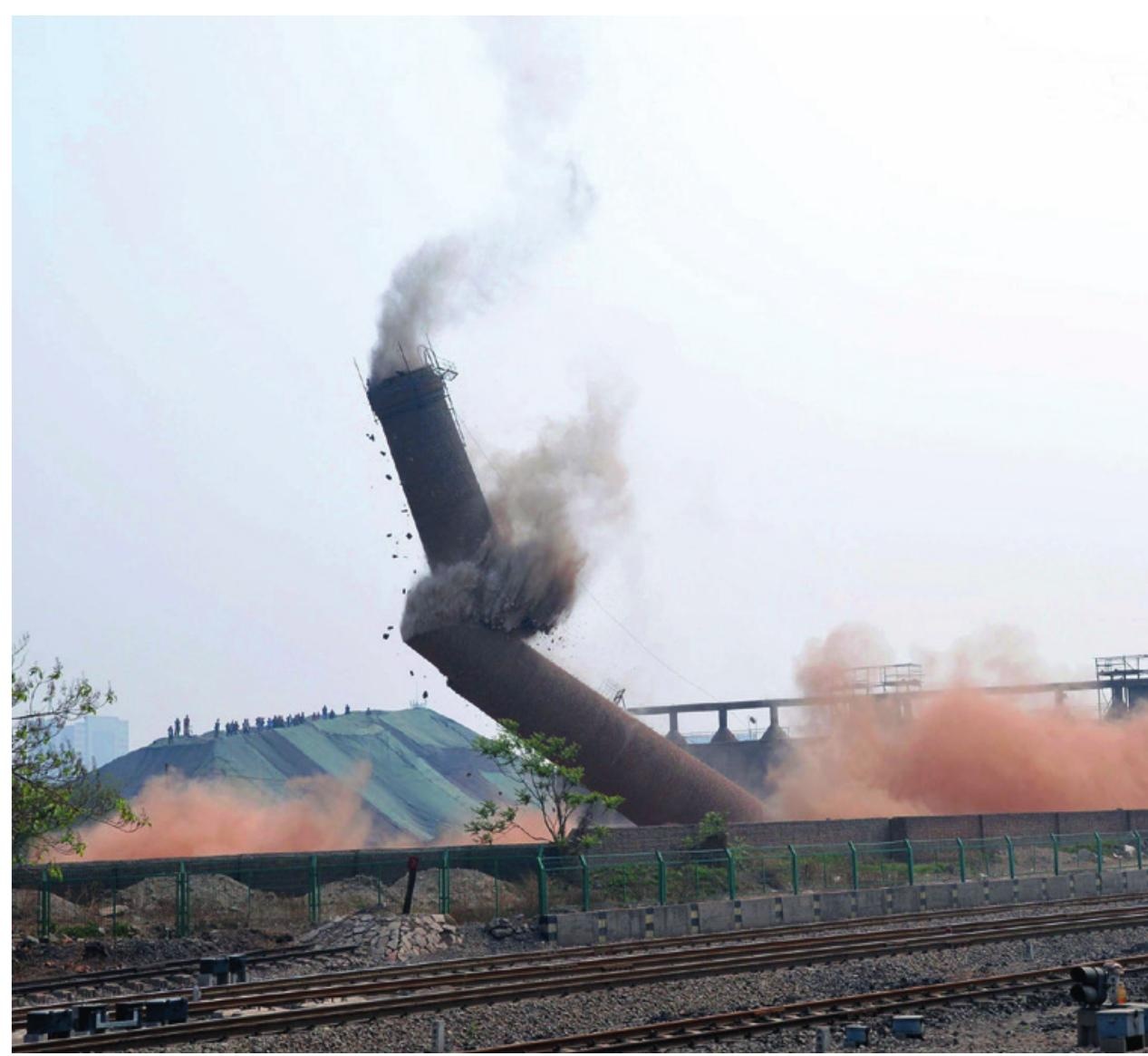

Fossil-fuel factories are demolished in China's Hebei province.

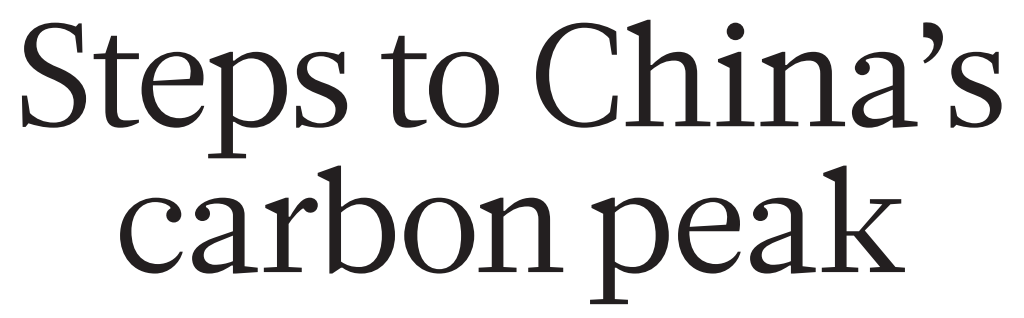

Regional targets and improved market mechanisms could enable the nation's carbon dioxide emissions to peak by 2030, say Zhu Liu and colleagues.

I n 2013, China released one-quarter of the global total of carbon dioxide for the year, and 1.5 times that released by the United States. It is the world's leading emitter of the gas. Without mitigation, China's $\mathrm{CO}_{2}$ emissions will rise by more than $50 \%$ in the next 15 years. Last November, in a joint announcement with the United States, China pledged that its $\mathrm{CO}_{2}$ emissions will peak by 2030 . Existing policies are insufficient to make that happen.

China has a two-pronged strategy for tackling climate change - increasing energy efficiency in manufacturing, and controlling regional emissions through targets. This approach has been effective: we calculate that $\mathrm{CO}_{2}$ emissions per unit gross domestic product (GDP) fell by $28.5 \%$ between 2005 and 2013. This is equivalent to a saving of more than 2.5 gigatonnes of $\mathrm{CO}_{2}$ (half of US total emissions). A fledgling domestic carbon-emissions-trading scheme (ETS) has slowed $\mathrm{CO}_{2}$ emissions growth by $2-3 \%$ in the seven provinces or cities in which it has been piloted.

But rapid economic growth, especially the building of infrastructure, has more than offset these reductions. Total national $\mathrm{CO}_{2}$ emissions grew by $7 \%$ each year between 2005 and 2013, although growth of emissions is slowing in cities such as Beijing and Shanghai as advanced technologies and cleaner energy sources are increasingly being used.

Curbing this growth will need a 
- decrease in projected emissions between 2015 and 2035 that is almost equivalent to the total global $\mathrm{CO}_{2}$ emissions in $2013-30$ gigatonnes (see 'Carbon crunch'). This challenging goal is within reach if China keeps its annual growth in emissions below $2 \%$, rolls out a national carbon-trading system and obtains $30 \%$ of its energy from renewables and natural gas by around 2035. China's per capita emissions in 2030 would then mirror those of the European Union (EU) in 2013 (a little under 8 tonnes of $\mathrm{CO}_{2}$ per person).

We propose four steps for China to hit this ambitious target. It must strengthen regional emissions targets; improve the reporting and verification of emissions data; enhance the regulation and supervision of a nationwide emissions-trading market; and incentivize the uptake of green technologies, especially in underdeveloped regions.

Set regional emissions targets. A single target will not be suitable for all of China's 30 provinces and autonomous regions, which have different energy-source mixes, uses and economic development needs. Peak emissions targets need to be designed for each region such that the national total falls by 2030 .

Wealthy cities such as Beijing, Tianjin and Shanghai, which have reversed emissions growth since 2011, could cap their emissions and set and adjust reduction targets at fiveyear intervals. Developed coastal provinces, such as Guangdong, Zhejiang and Jiangsu, that have benefited from the pilot ETS since 2010 should pledge more-aggressive and earlier peak targets - for example, reducing carbon emissions per capita to below those of the EU before 2030 or even 2020. Emissions in underdeveloped regions such as Shanxi province and the Ningxia and Xinjiang autonomous regions could be allowed to peak after 2030 to leave room for more infrastructure construction.

Fossil-fuel use needs to be curtailed first. The country's ambitious plan to cap national coal consumption in 2015 at 3.9 gigatonnes must be met. Beijing and Tianjin are required to halve their coal consumption by 2017 to meet mandated air-quality requirements. All conventional coal-fired plants in Beijing will be converted to gas by the end of 2015 and an extra 13 billion cubic metres of natural gas from western China and 12 billion cubic metres from other countries are being piped to Beijing and the surrounding cities. Smaller cities and other regions, too, must reduce their coal use.

China can strengthen technology-driven improvements in emission intensity $\left(\mathrm{CO}_{2}\right.$ emissions per unit of GDP), especially in the less developed regions. But loopholes also need to be closed. For instance, two-thirds of regions achieved their 2002-09 intensityreduction targets by enlarging the scale of

production ${ }^{1}$, which increased national emissions by $50 \%$ (ref. 2). To end this practice, emission-intensity targets should be supplemented by indicators of physical emissions efficiency, for example, emissions per unit of steel production. Such indicators are easier to monitor and verify and can be used to measure the efficiency of sectors, as well as of individual factories.

Air-quality indicators, such as particulate concentrations, should be integrated with emissions targets. Duplicate investments and work plans are common, with China's National Development and Reform Commission (NDRC) in charge of climatechange mitigation and the Ministry of Environment responsible for air-pollution abatement. Better coordination between departments and a set of joint emissionscontrol measures - managed by one agency - are needed.

Emissions targets must be decoupled from GDP. Criteria by which local and provincial leaders are evaluated for career promotion should include energy efficiency and pollution-abatement targets, rather than measures of economic development. Otherwise, greater growth will always trump environmental sustainability.

Ensure transparent emissions monitoring, reporting and verification. Data sets for China's total carbon emissions, especially those generated by regions and sectors, are not always reliable. Official national emissions totals have differed from self-reported provincial statistics by $20 \%$. And in sectoral data sets, factories may overstate their emissions to make it easier for them to achieve reduction targets ${ }^{3}$.

Also, the average carbon content of China's coal is not accurately known, given the variation in the quality of coal used across different regions.

As a first step, the Chinese Academy of Sciences is coordinating a national investi-

"China
produced
$60 \%$ of the
world's solar
photovoltaic
cells in 2014,
yet less than
$5 \%$ were
installed
domestically."
gation of major emissions sources and sinks that should be complete by the end of this year ${ }^{4}$. This should be expanded to include private and small-scale enterprises, which tend to use inefficient and dirty technologies. Small boilers, for example, consume about $10 \%$ of China's coal and are one of the main sources of air pollution in Beijing.

The compilation and reporting of local emissions data are coordinated by regional environmental-protection departments, which also issue environmental certificates for firms and construction projects. This conflict of interest sometimes leads to data manipulation and bribery; each year, hundreds of government officers are investigated.

The government needs to set up an independent agency to monitor and verify emissions data for regions, sectors and companies. The regulator would establish baseline emissions inventories and verify reductions through spot inspections, modelling and the installation of tamper-proof monitoring equipment.

Monitoring by third parties - the public, the media and non-governmental organizations (NGOs) - needs to be encouraged. Environmental laws and regulations must offer citizens the right to know emissions figures and the right to sue an agency or company if information has been concealed or manipulated.

State-owned projects should make information available to the public by publishing it online, as is done with Beijing's air-quality data. More web portals should be established to show the improvement, or lack of it, in pollution reduction over time. Examples include the Air Quality Index map (see go.nature. com/82gvyn), run by a Beijing-based NGO, and the pollution map produced by the non-profit Institute of Public and Environmental Affairs in Beijing, which displays real-time emissions information for more than 6,000 large-scale enterprises in China (see go.nature.com/vb6uht). Such efforts will enable government regulators and citizens' groups to 'name and shame' companies that do not adhere to environmental regulations.

Expand carbon trading nationwide. China's pilot ETS traded nearly 14 megatonnes of $\mathrm{CO}_{2}$ in 2013 . This is less than $0.5 \%$ of the national total, but the scheme is still the second largest in the world, after that of the EU. Starting in 2016-17 (ref. 5), the NDRC intends to extend the scheme to all $30 \mathrm{Chi}$ nese provinces, making China the world's largest carbon market. In the pilot ETS, each participant set its own cap and decided which sectors it would cover. For example, transport is included only in Shanghai's ETS. Each also determined how compliance is measured. Hubei province targets enterprises consuming more than 60,000 tonnes of coal-equivalent per year, a threshold six times that of Guangdong.

In the expanded scheme, a national emissions cap must be set and central government should develop standards and a timeline to unify cap criteria across the country. The first step should be to introduce a national ETS for the top six $\mathrm{CO}_{2}$-emitting industries - power generation, ferrous and non-ferrous metallurgy, construction, chemicals production and aviation services — to be extended later to others. Regulations and laws are needed that mandate emissions caps for certain enterprises and encourage emissions trading. Accounting and tax 


\section{CARBON CRUNCH}

China's carbon dioxide emissions will grow beyond the year 2030 unless it adopts strict low-carbon measures.

Greater production efficiency, use of renewable energies and natural gas, and nationwide emissions-trading schemes can allow emissions to peak by 2030, and reduce national $\mathrm{CO}_{2}$ emissions by 30 gigatonnes (Gt) by 2035 .

1 Projected emissions, with and without mitigation

2

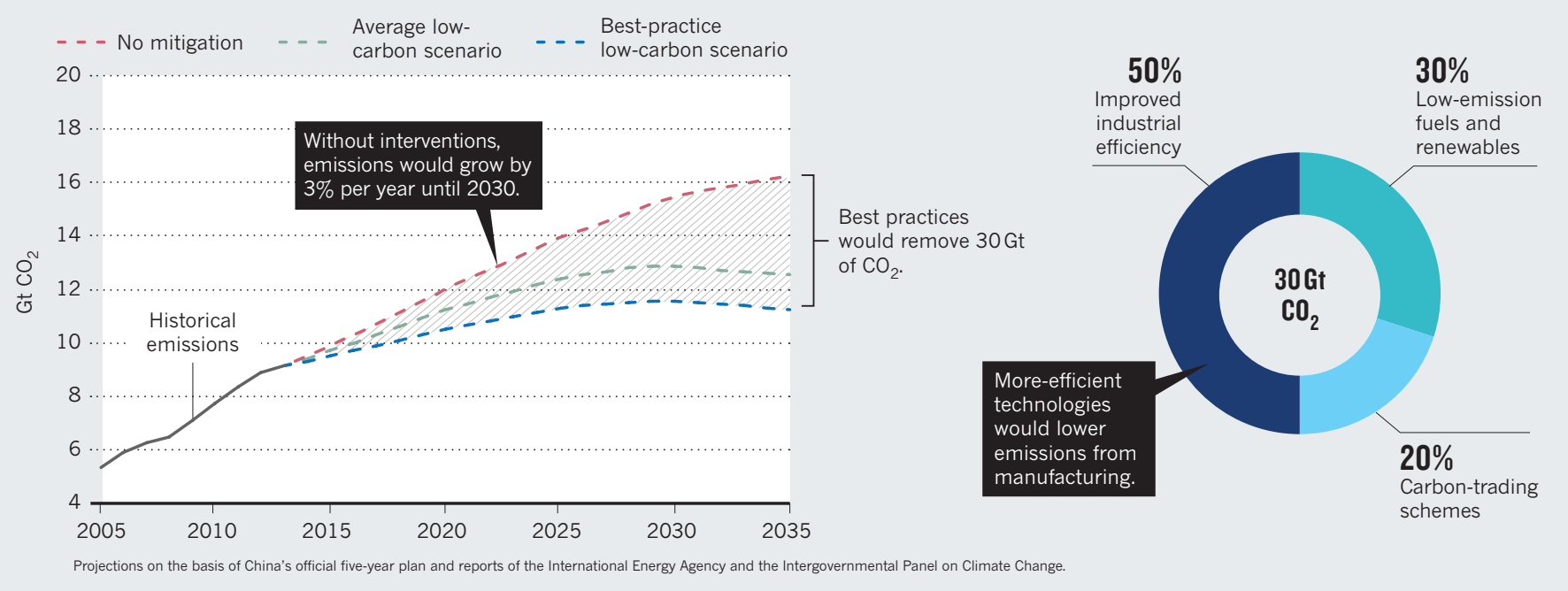

treatments need to be clarified.

A cascading management framework of carbon trading needs to be established, with provincial ETS exchanges linked to higherlevel, regional exchanges. For example, Beijing's exchange could coordinate provincial exchanges across northern China.

Market mechanisms should also be introduced to the energy-supply system. First, the monopoly of electricity and energy supply by major state-owned companies must be broken to encourage innovation and improved efficiency. PetroChina and Sinopec, the two main state-owned oil companies, together account for $80 \%$ of the national oil supply and $10 \%$ of the nation's total carbon emissions.

Second, an energy-supply market needs to be set up to allow prices to respond to demand and incentives. The price for energy delivered to the grid is now controlled by the government and is largely static. This creates barriers to the connection of power from renewable sources: low-carbon electricity is sold at a higher price than electricity generated from fossil fuels. Subsidies for fossil fuels, such as the contract price of coal sold to power plants, need to be removed so that renewables and low-carbon energy technology can be competitive. A carbon tax starting low and ratcheting up over the next decade - on certain emissions-intensive sectors, such as transport, that are susceptible to a change in behaviour would slow the growth in fossil-fuel consumption.

Advance green technology in underdeveloped areas. Government incentives have stimulated double-digit growth in renewable-energy technologies in the past decade. The 'green-energy' industry will contribute $2 \%$ of GDP $(45,000$ billion yuan) to the economy by the end of 2015 . Yet the nation's focus is still on manufacturing rather than implementation. China manufactured wind-power capacity equivalent to 114,763 megawatts in 2014 (half of the world's added capacity for the year), but only one-third of that operates in the country. China also produced $60 \%$ of the world's solar photovoltaic cells in 2014, yet less than $5 \%$ of these panels were installed domestically.

Incentives should be targeted to domestic consumers of renewable energy and eco-products, instead of encouraging production for the global market. Low-carbon technologies should be targeted especially at power production in China's underdeveloped and poor regions. These regions provide power and goods for others and stand to gain most from generation efficiency and development.

In 2010, for example, the emission factor $\left(\mathrm{CO}_{2}\right.$ emissions per kilowatt-hour of electricity generated) of coal-fired thermal power plants in Inner Mongolia was 20\% higher than that of power plants in Guangdong on the south coast ${ }^{3}$. Yet one-third of the power generated by Inner Mongolia is exported to the east-coast regions ${ }^{6}$. Poor central and western provinces should instead exploit their vast land areas for solar and wind farms.

Regional grid construction and integrated technologies should be encouraged. China is a world leader in ultra-high-voltage transmission technology. This will be essential for linking areas generating renewable electricity, mainly in the west, to the large coastal cities. Initiatives to develop 'smart' electricity grids and high-speed connections would save energy through improving electricity distribution. Mass-transit systems and regional rail expansion would similarly reduce emissions from road traffic and construction.

We call on China's leaders to be bold and create a low-carbon economy that will benefit the country and the globe.

Zhu Liu is at the Institute of Applied Ecology, Chinese Academy of Sciences, Shenyang, China. Dabo Guan is at the School of International Development, University of East Anglia, Norwich, UK. Scott Moore, Henry Lee and Z.L. are at the John F. Kennedy School of Government, Harvard University, Cambridge, Massachusetts, USA. Jun Su is at the School of Public Policy and Management, Tsinghua University, Beijing, China. Qiang Zhang and D.G. are at the Center for Earth System Science, Tsinghua University, Beijing, China. e-mails:dabo.guan@uea.ac.uk; liuzhu@iae.ac.cn

1. Guan, D. et al. Nature Clim. Change 4, $1017-$ 1023 (2014)

2. Liu, Z., Geng, Y., Lindner, S. \& Guan, D. Energy 45, 1059-1068 (2012)

3. Guan, D., Liu, Z., Geng, Y., Lindner, S. \& Hubacek, K. Nature Clim. Change 2, 672-675 (2012).

4. Jiao, L. \& Stone, R. Science $\mathbf{3 3 4 , 8 8 6 - 8 8 7}$ (2011).

5. National Development and Reform Commission of China. Interim Plan for Carbon Trading in China (NDRC, 2014).

6. Feng. K. Proc. Natl Acad. Sci. USA 110, 11654 11659 (2013). 